\title{
Apparent interfacial shear strength of short-flax-fiber/starch acetate composites
}

\author{
Andersons, J.; Modniks, J.; Joffe, R.; Madsen, Bo; Nättinen, K.
}

Published in:

International Journal of Adhesion and Adhesives

Link to article, DOI:

10.1016/j.ijadhadh.2015.10.007

Publication date:

2016

Document Version

Peer reviewed version

Link back to DTU Orbit

Citation (APA):

Andersons, J., Modniks, J., Joffe, R., Madsen, B., \& Nättinen, K. (2016). Apparent interfacial shear strength of short-flax-fiber/starch acetate composites. International Journal of Adhesion and Adhesives, 64, 78-85. https://doi.org/10.1016/j.ijadhadh.2015.10.007

\section{General rights}

Copyright and moral rights for the publications made accessible in the public portal are retained by the authors and/or other copyright owners and it is a condition of accessing publications that users recognise and abide by the legal requirements associated with these rights.

- Users may download and print one copy of any publication from the public portal for the purpose of private study or research.

- You may not further distribute the material or use it for any profit-making activity or commercial gain

- You may freely distribute the URL identifying the publication in the public portal 


\section{Author's Accepted Manuscript}

Apparent interfacial shear strength of short-flaxfiber/starch acetate composites

J. Andersons, J. Modniks, R. Joffe, B. Madsen, K. Nättinen

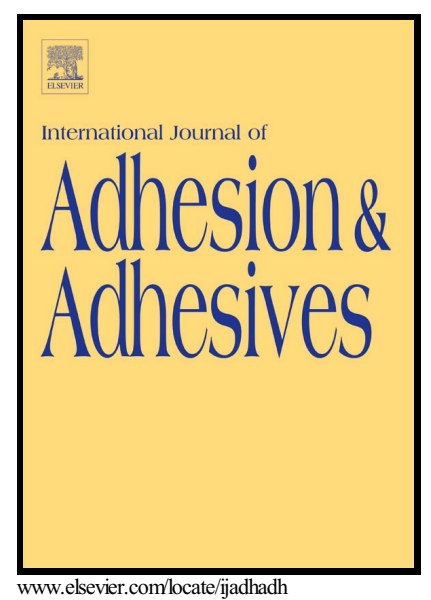

PII: $\quad$ S0143-7496(15)00160-8

DOI: $\quad$ http://dx.doi.org/10.1016/j.ijadhadh.2015.10.007

Reference: JAAD1718

To appear in: International Journal of Adhesion and Adhesives

Received date: 26 November 2014

Accepted date: 30 September 2015

Cite this article as: J. Andersons, J. Modniks, R. Joffe, B. Madsen and K Nättinen, Apparent interfacial shear strength of short-flax-fiber/starch acetat composites, International Journal of Adhesion and Adhesives http://dx.doi.org/10.1016/j.ijadhadh.2015.10.007

This is a PDF file of an unedited manuscript that has been accepted fo publication. As a service to our customers we are providing this early version o the manuscript. The manuscript will undergo copyediting, typesetting, an review of the resulting galley proof before it is published in its final citable form Please note that during the production process errors may be discovered whic could affect the content, and all legal disclaimers that apply to the journal pertain 


\section{ACCEPTED MANUSCRIPT}

Apparent interfacial shear strength of short-flax-fiber/starch acetate composites

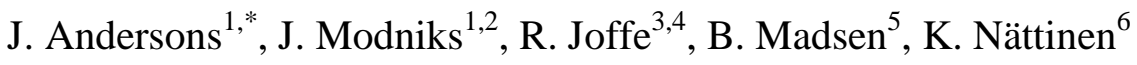

${ }^{1}$ Institute of Polymer Mechanics, University of Latvia, Aizkraukles st. 23, Rīga, Latvia

${ }^{2}$ Ventspils University College, Inženieru str. 101, Ventspils, Latvia

${ }^{3}$ Composite Centre Sweden, Luleå University of Technology, SE-971 87 Luleå, Sweden

${ }^{4}$ Swerea SICOMP, P.O. Box 271, S-94126 Piteå, Sweden

${ }^{5}$ Department of Wind Energy, Technical University of Denmark, Risø Campus, Roskilde,

Denmark

${ }^{6}$ Bemis Flexible Packaging Europe, Bemis Valkeakoski Oy, Teollisuustie 1, 37601

Valkeakoski, Finland

*Corresponding author. Tel.: +371 67543327; Fax +371-67820467;

E-mail address: janis.andersons@pmi.lv 


\title{
ACCEPTED MANUSCRIPT
}

\begin{abstract}
.
The paper deals with an indirect industry-friendly method for identification of the interfacial shear strength (IFSS) in a fully bio-based composite. The IFSS of flax fiber/starch acetate is evaluated by a modified Bowyer and Bader method based on an analysis of the stress-strain curve of a short-fiber-reinforced composite in tension. A shear lag model is developed for the tensile stress-strain response of short-fiber-reinforced composites allowing for an elasticperfectly plastic stress transfer. Composites with different fiber volume fractions and a variable content of plasticizer have been analyzed. The apparent IFSS of flax /starch acetate is within the range of 5.5 to $20.5 \mathrm{MPa}$, depending on composition of the material. The IFSS is found to be greater for composites with a higher fiber loading and to decrease with increasing content of plasticizer. The IFSS is equal or greater than the yield strength of the neat polymer, suggesting good adhesion, as expected for the chemically compatible constituents.
\end{abstract}

Key-words: green composite, interfacial shear strength, flax fiber, thermoplastic starch 


\section{ACCEPTED MANUSCRIPT}

\section{Introduction}

In order to reduce the environmental impact of composite materials, natural fibers and biobased matrices are considered as a replacement for the traditional, man-made reinforcements and the matrices derived from petrochemical resources. The production methods and mechanical properties of such green, biodegradable composites manufactured from renewable constituents are being studied extensively as reflected in recent reviews [1-4]. The worldwide capacity of bio-based plastics is expected to increase almost tenfold by 2020 compared with that in 2007, with starch-based plastics among the leading products in terms of production volume $[1,2]$. Among natural, plant-derived fibers, bast fibers arguably possess the highest potential for reinforcement due to their superior specific axial mechanical properties imparted by a combination of the high content of crystalline cellulose and the low microfibril angle with fiber axis [5].

Since the quality of the interface between the matrix and fibers exerts a major effect on the mechanical properties of composite materials, the compatibility of their constituents is also an important issue for green composites. It has been argued in [6] that acetylation of the free hydroxyl groups of starch with a degree of substitution higher than 2 but lower than 3 , while making the material melt-processable, still retains a sufficient hydroxyl functionality in starch acetate for hydrogen bonding with cellulosic fibers. Short-bast-fiber composites with a starch acetate matrix (with a degree of acetylation evaluated at 2.6) and different content of plasticizer were produced and characterized [6]. While the stiffness [7] and tensile strength [8] of the composites have been subjected to detailed studies, the evaluation of the fiber/matrix adhesion achieved has been addressed only via an analysis of composite strength [8].

A commonly used parameter characterizing the adhesion between a fiber and matrix is the interfacial shear strength (IFSS). An extensive range of test methods has been developed for the IFSS, see, e.g., [9], which are also applied to natural fibers. Although the values of 


\section{ACCEPTED MANUSCRIPT}

IFSS obtained by different methods may not coincide exactly, the results of several commonly used test methods, such as pull-out, microbond, and single fiber fragmentation tests showed the same trends for cellulose (flax, kenaf, Lyocell) fibers [10]. In terms of ease of implementation, the evaluation of IFSS based on an analysis of the stress-strain response of short-fiber-reinforced composites in tension appears to be the most industry-friendly adhesion test method [11]. As originally proposed in $[12,13]$, the IFSS and the fiber orientation factor are evaluated from experimental measurements of composite stress at two different values of applied strain within the nonlinear deformation range, assuming a linear elastic matrix response. The method was further developed in [11, 14-16] by taking into account the nonlinearity of the matrix response in tension. Subsequently, using the whole experimental stress-strain curve of the composite, rather than only two points, was proposed in $[17,18]$ for estimation of its IFSS. The composite-test-based approach has also been applied to the evaluation of the IFSS of natural fibers, such as, e.g., flax [19-21], hemp [22-24], corn stalk [25], stone groundwood [26], old newspaper [27], and orange tree pruning pulp [28] fibers and polypropylene matrices, as well as hemp fibers and a Mater- $\mathrm{Bi}^{\circledR}$ thermoplastic starch matrix [29].

The distribution of stress in reinforcing fibers has been modeled in [12-18] assuming that the stress transfer takes place via a rigid-perfectly plastic interfacial shear response [30]. While such an approach is well substantiated for relatively high strains, neglecting the effect of elastic stress transfer appears to be questionable for small to intermediate strain range, which is also taken into account when the whole stress-strain curve is employed for estimation of the IFSS, as, e.g., in [17, 18]. More advanced models of elastic-plastic deformation of short-fiber-reinforced composites, allowing for matrix plasticity and interfacial debonding of fibers, have been developed in, e.g., [31-34], but their application for identification of the IFSS is complicated by the necessity of an extensive numerical analysis [31] or identification 


\section{ACCEPTED MANUSCRIPT}

of a set of damage parameters [32-34]. In the current study, an elementary shear lag model is developed for the tensile stress-strain response of short-fiber-reinforced composites allowing for an elastic-perfectly plastic stress transfer. The model is applied for evaluation of the apparent IFSS of flax/starch acetate composites with a variable content of plasticizer, produced and tested as described in [6].

\section{Materials and methods}

The constituents, production, morphological analysis, and testing of short-flax-fiber reinforced starch acetate composites has been described in $[6,7]$; below, for completeness and the ease of reference, we briefly recapitulate the relevant information.

The flax fibers were supplied by Ekotex, Poland, and an amylose-rich corn starch was obtained from Gargill, USA (Cerestar Amylogel 03003: 65 wt.\% amylose and 35 wt.\% amylopectin). The processes of fiber pelletizing, starch acetylation, and plasticization, as well as the compounding, post-processing, and injection molding of composites and the manufacturing of tensile specimens are described in detail in [6]. Nine flax/starch composites differing in the content of plasticizer and fibers, as summarized in Table 1, were produced.

Prior to the mechanical testing, the tensile specimens were conditioned at $23{ }^{\circ} \mathrm{C}$ and $50 \% \mathrm{RH}$ for a minimum of five days. The tensile specimens were tested according to the ISO 527 standard on an Instron 4505 Universal Tensile Tester with a $10 \mathrm{kN}$ load cell and a crosshead speed of $5 \mathrm{~mm} / \mathrm{min}$. The strain was measured by an Instron 2665 Series High Resolution Digital Automatic Extensometer. The testing was performed at controlled ambient conditions: $23^{\circ} \mathrm{C}$ and a relative humidity of $50 \%$. The cross-sectional dimensions of the gauge area section of each tensile specimen were measured with a slide gauge $( \pm 0.01 \mathrm{~mm})$. Young's modulus was evaluated as the slope of the experimental stress strain diagram within the strain range of 0.1 to $0.3 \%$. 


\section{ACCEPTED MANUSCRIPT}

The volume fractions of constituents were determined by using gravimetric measurements of the densities of fibers, matrix, and composites and the known fiber weight fraction in the composites (as described in detail in [6]). Fiber dimensions (length and diameter) were determined from fibers extracted from composites (the matrix was dissolved in hot chloroform) by optical microscopy and image analyses (see [7] for details). The average apparent fiber diameter and the aspect ratio, defined as the ratio of the average fiber length to its average diameter, for the composites considered are provided in Table 1.

\section{An elementary model of the non-linear stress-strain response of a short-fiber- reinforced composite}

It has been suggested in $[12,13]$ that the non-linear stress-strain diagram in tension of a shortfiber-reinforced composite can be evaluated by the rule-of-mixtures approach, expressing the composite stress $\sigma_{c}$ at an applied strain $\varepsilon$ as the sum of fiber and matrix contributions. The resulting relation can be recast as follows:

$\sigma_{c}=\eta_{o} \eta_{l} v_{f} E_{f} \varepsilon+\left(1-v_{f}\right) \sigma_{m}$,

where $\eta_{o}$ and $\eta_{l}$ stand for the fiber orientation and length efficiency factors, $v_{f}$ is the fiber volume fraction in the composite, $E_{f}$ denotes the longitudinal modulus of linear elastic reinforcing fibers, and $\sigma_{m}$ is the axial stress acting in the matrix. The non-linearity of the composite response may stem from the nonlinear deformation of matrix, $\sigma_{m}=\sigma_{m}(\varepsilon)$, and the inelastic stress transfer between the constituents. The latter, for the specific case of a rigidperfectly plastic interfacial shear response, has been considered in $[12,13]$.

In the following sections, we recapitulate the classical linear elastic shear lag relations and consider expressions of the fiber length efficiency factor $\eta_{l}$ in Eq. (1) for the elastic- 


\section{ACCEPTED MANUSCRIPT}

perfectly plastic and rigid-perfectly plastic stress transfer between the fibers and matrix by shear.

\subsection{Linear elastic stress transfer}

At small strains, the fibers, matrix, and stress transfer between them can be considered linear elastic. According to the shear lag model [35], the distribution of axial stress $\sigma_{f}$ in a fiber of length $l$, shown schematically in Fig. 1a, embedded in the matrix and aligned with the loading direction, is

$$
\sigma_{f}=E_{f} \varepsilon\left(1-\frac{\cosh \beta x}{\cosh \beta l / 2}\right),
$$

and the interfacial shear stress is expressed as

$$
\tau=-\frac{E_{f} \varepsilon \beta r_{f}}{2} \frac{\sinh \beta x}{\cosh \beta l / 2}
$$

where $r_{f}$ designates the fiber radius and $\beta$ is the shear lag parameter. For hexagonal fiber packing [36],

$\beta=\frac{2}{r_{f}} \sqrt{\frac{2 G_{m}}{E_{f} \ln \left(\pi / 2 \sqrt{3} v_{f}\right)}}$,

with $G_{m}$ denoting the shear modulus of matrix. The axial stress distribution Eq. (2) for a fiber of length exceeding that of the stress transfer zone $(l>>1 / \beta)$ is shown schematically in Fig. $1 b$.

The length efficiency factor $\eta_{l}$, defined as the ratio of the average fiber stress, $\left\langle\sigma_{f}\right\rangle$, to the nominal stress $E_{f} \varepsilon, \eta_{l}=\left\langle\sigma_{f}\right\rangle / E_{f} \varepsilon$, for a fiber of length $l$, is equal to

$$
\eta_{l}^{*}(l)=1-\frac{\tanh \beta l / 2}{\beta l / 2}
$$

If the length of reinforcing fibers is variable with a distribution density $p(l)$, the fiber length efficiency factor is determined as [37] 
$\eta_{l}=\frac{1}{\langle l\rangle} \int_{0}^{\infty} \eta_{l}^{*}(l) l p(l) d l$

where $\langle l\rangle$ is the mean fiber length. The well-known rule of mixtures, as applied to the Young's modulus of the composite, at small strains, implying a linear elastic matrix response, follows from Eq. (1):

$E_{c}=\eta_{o} \eta_{l} E_{f} v_{f}+\left(1-v_{f}\right) E_{m}$,

where $E_{m}$ is the Young's modulus of matrix.

\subsection{Elastic-plastic stress transfer}

The peak interfacial shear stress $\tau_{\max }$ a fiber experiences is reached at fiber ends; its value in an elastic stress transfer is proportional to the applied strain and, according to Eq. (3), is given by

$\tau_{\max }=\frac{E_{f} \varepsilon \beta r_{f}}{2} \tanh \frac{\beta l}{2}$

For the elastic-perfectly plastic stress transfer by shear, the fiber length $l_{e l}$ at the onset of interfacial yielding depends on the limit shear stress $\tau_{i}$ as follows from Eq. (8):

$l_{e l}=\frac{2}{\beta} \tanh ^{-1} \frac{2 \tau_{i}}{E_{f} \varepsilon \beta r_{f}}$.

With increasing applied strain, a yield zone of length $l_{p}$ with a constant interfacial shear stress $\tau_{i}$ develops at fiber ends, affecting the distribution of the axial stress in the fiber as shown schematically in Fig. 1c. The distributions of fiber and interfacial shear stresses have been derived in [38] by using a shear lag analysis for a cylindrical unit cell. In the following, we recast their solution for the general shear lag conditions, unrestricted to a specific unit cell geometry. 


\section{ACCEPTED MANUSCRIPT}

Due to symmetry of the problem, we consider only the half of the fiber with $x>0$, see

Fig. 1a. Along the interfacial yielding zone, the shear stress is constant:

$\tau(x)=-\tau_{i}, \quad l / 2-l_{p} \leq x \leq l / 2$.

Integration of the equilibrium equation

$\tau(x)=\frac{r_{f}}{2} \frac{d \sigma_{f}(x)}{d x}$

for the stress-free fiber ends, $\sigma_{f}( \pm l / 2)=0$, leads to the axial stress in the fiber in the interfacial yielding region as follows:

$\sigma_{f}(x)=\frac{2 \tau_{i}}{r_{f}}(l / 2-x), \quad l / 2-l_{p} \leq x \leq l / 2$

In the middle zone of the fiber, experiencing the elastic stress transfer, the symmetric part of the general solution [35] for axial fiber stress applies:

$\sigma_{f}(x)=E_{f} \varepsilon+C \cosh \beta x, \quad 0 \leq x \leq l / 2-l_{p}$,

where $C$ is a constant. It follows from Eqs. (11) and (13) that the interfacial shear stress in this zone varies as

$\tau(x)=\frac{C \beta r_{f}}{2} \sinh \beta x, \quad 0 \leq x \leq l / 2-l_{p}$

Enforcing the continuity of shear, Eqs. (10) and (14), and axial, Eqs. (12) and (13), stresses at $x=l / 2-l_{p}$ provides a system of two equations that can be solved explicitly for the constant

$C:$

$C=-\frac{E_{f} \varepsilon-\frac{2 \tau_{i}}{r_{f}} l_{p}}{\cosh \beta\left(l / 2-l_{p}\right)}$

whereas the length $l_{p}$ of the interfacial yielding region is given implicitly by the relation

$\operatorname{coth} \beta\left(l / 2-l_{p}\right)+\beta l_{p}=\frac{E_{f} \varepsilon \beta r_{f}}{2 \tau_{i}}$ 


\section{ACCEPTED MANUSCRIPT}

It follows from Eq. (5) for $l \leq l_{e l}$ and Eqs. (12), (13), and (15) for $l>l_{e l}$ that the efficiency factor of a fiber of length $l$ is

$\eta_{l}^{*}(l)=\left\{\begin{array}{cc}1-\frac{\tanh \beta l / 2}{\beta l / 2} & l \leq l_{e l} \\ 1-\left(1-\frac{2 \tau_{i} l_{p}}{E_{f} \varepsilon r_{f}}\right) \frac{\tanh \beta\left(l / 2-l_{p}\right)}{\beta l / 2}-\frac{2 l_{p}}{l}\left(1-\frac{\tau_{i} l_{p}}{E_{f} \varepsilon r_{f}}\right) & l>l_{e l}\end{array}\right.$

In the case of reinforcing fibers with a variable length, the length efficiency factor should be estimated by substituting Eq. (17) into Eq. (6).

\subsection{Rigid-perfectly plastic stress transfer}

It follows from $[30,12,13]$ that the length efficiency factor of a fiber of length $l$ under rigidperfectly plastic stress transfer reads as

$\eta_{l}^{*}(l)=\left\{\begin{array}{cc}\frac{l}{2 l_{c}} & l \leq l_{c} \\ 1-\frac{l_{c}}{2 l} & l>l_{c}\end{array}\right.$

where the critical fiber length $l_{c}$ is defined as

$l_{c}=\frac{E_{f} \varepsilon}{\tau_{i}} r_{f}$.

For the scatter of fiber lengths complying with the two-parameter Weibull distribution

$$
P(l)=1-\exp \left[-\left(\frac{l}{l_{W}}\right)^{\alpha}\right],
$$

the integral in Eq. (6), with $\eta_{l}^{*}(l)$ given by Eq. (18) and length distribution density being the first derivative of Eq. (20), can be evaluated analytically, yielding

$$
\eta_{l}=\frac{\Gamma\left(1+\frac{1}{\alpha},\left(\frac{l_{c}}{l_{W}}\right)^{\alpha}\right)+\frac{l_{W}}{\alpha l_{c}}\left[\Gamma\left(\frac{2}{\alpha}\right)-\Gamma\left(\frac{2}{\alpha},\left(\frac{l_{c}}{l_{W}}\right)^{\alpha}\right)\right]-\frac{l_{c}}{l_{W}} \exp \left[-\left(\frac{l_{c}}{l_{W}}\right)^{\alpha}\right]}{\Gamma\left(1+\frac{1}{\alpha}\right)},
$$




\section{ACCEPTED MANUSCRIPT}

where $\Gamma$ designates the gamma function.

Note that Eq. (21) differs from an analogous expression introduced in [17], because the latter has been derived implicitly defining $\eta_{l}$ as the average value of $\eta_{l}^{*}(l)$ given by Eq. (18), i.e., as $\eta_{l}=\int_{0}^{\infty} \eta_{l}^{*}(l) p(l) d l$. It has been demonstrated in [37] that such an approach is incorrect and leads to underestimation of the fiber length efficiency factor (also see Appendix for an alternative elementary derivation of $\eta_{l}$ ).

\section{Results and discussion}

As an estimate of the apparent IFSS, the value of $\tau_{i}$ providing best fit of Eq. (1) to the experimental stress-strain diagrams of short-fiber-reinforced composites at two strain levels [11-16] or in the whole strain range [17-18] is employed. Both the IFSS and the fiber orientation factor are evaluated simultaneously in [11-18]. However, it has been confirmed experimentally in [39] that the rule of mixtures, Eq. (7), can be employed to obtain the fiber orientation factor along a particular axis if the rest of parameters in the stiffness model are known. Expressing $\eta_{o}$ from Eq. (7) yields

$\eta_{o}=\left(E_{c}-\left(1-v_{f}\right) E_{m}\right) / \eta_{l} E_{f} v_{f}$

Determining $\eta_{o}$ by Eq. (22) from the linear elastic response of the composite, characterized by Young's modulus $E_{c}$, leaves the IFSS as the only parameter to be estimated from the complete stress-strain diagram.

Note that a multiplicative correction factor equal to $\left(1-v_{p}\right)^{2}$ has been introduced into the rule of mixtures relation for natural-fiber composites in [40], reflecting the detrimental effect of porosity, characterized by void content $v_{p}$, on their stiffness. However, porosity in 


\section{ACCEPTED MANUSCRIPT}

the flax/starch composites considered was rather low, with a void volume fraction $v_{p}$ ranging from nearly 0 to 0.013 [7], therefore its effect is neglected in the present study.

In the further numerical analysis, the values of Young's modulus $E_{m}$ for matrices with a variable content of plasticizer as reported in $[1,7]$ are used, and Poisson's ratio of 0.3 for the neat polymers is adopted as in [7]. The axial stiffness of the reinforcing flax fibers is assumed at $E_{f}=50 \mathrm{GPa}$ [7]; the values of apparent fiber diameter from [7] are recapitulated in Table 1. The fiber volume fractions in the composites are provided in $[7,8]$. The parameters of fiber length distribution, Eq. (20), were determined by the maximum likelihood method, using a representative sample of fiber length measurements for each composite, and reported in Table 2. As an example, Fig. 2 shows an empirical length distribution of fibers extracted from composites designated as $\mathrm{C} 15$ and the approximation by the two-parameter Weibull distribution, Eq. (20), demonstrating reasonably good agreement.

Using the fiber, matrix, and composite characteristics specified above, the fiber length efficiency factors were calculated for each combination of the plasticizer content and fiber loading by Eqs. (5) and (6). Further, based on the $\eta_{l}$ estimates obtained and the experimental Young's moduli of the composites, the fiber orientation factors were determined by Eq. (22) for each specimen tested; the respective mean values and standard deviations are presented in Table 2.

The nonlinearity of the tensile response of matrix was allowed for in the composite response, Eq. (1), only via the matrix stress $\sigma_{m}=\sigma_{m}(\varepsilon)$; the shear lag factor $\beta$ evaluated by Eq. (4) using the elasticity characteristics of matrix was employed also in the region of nonlinear deformation. The stress-strain diagrams $\sigma_{m}(\varepsilon)$ of the neat matrix were approximated by a forth-order polynomial up to the $3 \%$ strain. 


\section{ACCEPTED MANUSCRIPT}

The representative experimental stress-strain curves of composites with the lowest, intermediate, and the highest content of plasticizer are shown in Fig. 3 together with their approximation, up to the maximum stress achieved during loading, by Eq. (1). The values of $\tau_{i}$ providing the best fit of Eq. (1) to the experimental diagrams are presented in Table 2 both for the elastic-plastic $\left(\right.$ IFSS $\left._{\mathrm{ep}}\right)$ and the rigid-plastic $\left(\mathrm{IFSS}_{\mathrm{rp}}\right)$ interfacial response.

The model of elastic-perfectly plastic stress transfer provides a uniformly good approximation of the experimental diagrams, as exemplified in Fig. 3. By contrast, the assumption of a rigid-perfectly plastic interfacial shear response tends to overestimate the stiffness of composites at the onset of loading. This is apparently caused by the unrealistically high value of the fiber length efficiency factor at small strains according to Eq. (18), with $\eta_{l}^{*}(l)$ approaching 1 as $\varepsilon \rightarrow 0$, which makes the predicted small-strain response of the composite stiffer than that according to the elastic stress transfer, cf. $\eta_{l}$ values in Table 2 . It is seen in Table 2 that the IFSS $\mathrm{rp}$ is consistently smaller than the IFSS $S_{\mathrm{ep}}$, but the relative difference does not exceed 15\%, apart from C16 and C17 composites. Notably, in the latter cases, the fiber aspect ratio, reported in Table 1, was comparatively small and the rigidperfectly plastic interface model also provided an inferior approximation of the experimental stress-strain diagrams, as seen in Fig. 3a for C16.

The apparent IFSS $_{\mathrm{ep}}$ as a function of plasticizer content in the matrix is shown in Fig. 4 for both the fiber loadings studied. Considering Mater-Bi ${ }^{\circledR}$, a thermoplastic biodegradable polymer made of starch, the values of IFSS obtained are in reasonable agreement with the IFSS estimate of ca. $16 \mathrm{MPa}$ for hemp-fiber composites at a fiber content of $20 \mathrm{wt} \%$ [29], while higher than the IFSS of 4.2 MPa determined by pull-out tests of flax fibers [41]. The IFSS evaluated using the tensile strength data of starch-based biopolymer Biopar ${ }^{\circledR}$ reinforced with 10,20 , and 30 wt.\% of short flax fibers ranged from 4.3 to $6.2 \mathrm{MPa}$ [42]. The apparent IFSS of flax/starch acetate also compares favorably with that of flax and such thermoplastic 


\section{ACCEPTED MANUSCRIPT}

polymers as polypropylene and polyethylene, reported to range from ca. 6 to $20 \mathrm{MPa}$ [43] depending on flax fiber type, surface treatment, and compatibilizer, and that of unsaturated polyester (13 to $15 \mathrm{MPa}$ ), while being somewhat inferior to the IFSS in the case of epoxy (24 to $33 \mathrm{MPa}$ ) and vinylester (20 to $31 \mathrm{MPa})[44]$.

It is seen in Fig. 4 that the IFSS decreases with increasing relative amount of plasticizer. Note that a reduction in the mechanical efficiency of the fiber/matrix interface with increase in plasticizer content has been reported in [45] for natural-cellulose-fiber (from leafwood) reinforced wheat-starch-matrix composites, with glycerol used as the plasticizer. This effect was attributed to the prevailing starch-cellulose interactions at a low content of plasticizer, and the hydroxyl carbohydrate sites becoming saturated with glycerol molecules at a higher content of glycerol [45]. It appears plausible that a similar mechanism accounts for the variation in IFSS presented in Fig. 4. Namely, the increase in plasticizer content results in dilution of the matrix - the chemical interactions of the fibers and starch matrix become increasingly mediated by the plasticizer molecules residing around the fiber hydroxyl as well as the starch acetate carbonyl groups, leading to a reduced adhesion.

At a higher content of plasticizer, the IFSS is not appreciably affected by the fiber loading, whereas the IFSS at $40 \%$ loading exceeds that at $10 \%$ at a lower content of plasticizer. In short-fiber composites, the IFSS has been found to either decrease with increasing content of inorganic [14-16, 46, 47] and natural [19-21, 24] fibers, stay approximately constant, $[48,49]$ and $[23,27]$, respectively, or even increase $[42,50]$ with it. It has been proposed in [51] that the apparent IFSS can be expressed as the sum of two components

$\tau_{i}=\tau_{0}+\mu \sigma_{r}$,

the first of which is due to physicochemical molecular interactions at the fiber/matrix interface, and the second, given by the product of the coefficient of static friction $\mu$ and the 


\section{ACCEPTED MANUSCRIPT}

absolute value of the residual compressive radial stress $\sigma_{r}$ acting on the lateral surface of the fibers, reflects the contribution of interfacial friction. The magnitude of the residual stress $\sigma_{r}$ decreases with increasing fiber volume fraction in polymer composites (see, e.g. [52, 53]), thus, according to Eq. (23), explaining the reduction in the apparent IFSS in the case of mechanical interlocking and friction-dominated load transfer between fibers and matrix. The latter is the stress transfer mechanism expected for natural fiber/polymer interfaces in the case of inferior chemical compatibility.

However, an appropriate compatibilization may render the intrinsic adhesion term $\tau_{0}$ dominating the apparent IFSS of such composites, as suggested by the results presented in $[23,26]$. Notably, the apparent IFSS was found to decrease by about $10 \%$ with fiber loading in stone groundwood fiber/PP composites increasing from 30 to $50 \%$ [26]. The addition of a coupling agent not only increased the IFSS by a factor of ca. 4 , but also made it independent of fiber loading [26]. Thus, the absence of reduction in the apparent IFSS with increase in fiber loading seen in Fig. 4 for the whole range of plasticizer contents studied suggests that the contribution of the frictional load transfer is negligible in flax/starch composites, with chemical interactions accounting for the adhesion, as would be expected due to the inherent compatibility of their constituents [6]. Note that a qualitatively similar variation in the IFSS with reinforcement content was also reported for flax/Biopar ${ }^{\circledR}$ [42] and alpha grass fiber/ Mater-Bi ${ }^{\circledR}$ composites [50].

The apparent IFSS is shown in Fig. 5 as a function of the shear yield strength of matrix. The latter was estimated from the tensile yield strength of the neat polymer, presented in Table 1, according to the von Mises relation. A strong correlation between the IFSS and the matrix yield strength is seen, with IFSS generally exceeding the yield strength. Similar behavior was observed in [8] where it has been shown for the composites studied in the 


\section{ACCEPTED MANUSCRIPT}

current paper that the IFSS values obtained from the best fit between predicted and measured strength are either equal or higher than the shear yield stress of matrix.

In comparison, the mean IFSS was lower than the shear yield strength estimated from the tensile strength of neat matrix by the von Mises criterion, but higher than that estimated by the Tresca criterion for old newspaper fiber/PP [27], hemp/PP [23], and hemp/Mater-Bi ${ }^{\circledR}[29]$ composites. The IFSS was close or slightly exceeding the von Misses estimate of the shear yield strength for pulp fiber/PP composites [28]. Thus, the relatively high values of IFSS of flax/starch composites suggest that the shear yielding and strain hardening of matrix at the fiber interface takes place before debonding. The difference in IFSS values at the same plasticizer content but different fiber loadings is likely to stem from the effect of confinement on the yield response of matrix discussed in [8].

\section{Conclusions}

The tensile stress-strain curves of short-flax-fiber/starch acetate composites with a variable content of plasticizer and fibers were analyzed with the purpose of evaluation of the interfacial shear strength. The modified Bowyer and Bader technique with a more realistic, elastic-perfectly plastic, representation of stress transfer between the fibers and matrix was applied. The apparent interfacial shear strength was found to depend on fiber loading in the composites and to decrease with increasing content of plasticizer in the matrix. Depending on material composition (i.e. the relative amount of fibers, starch acetate, and plasticizer), values of the interfacial shear strength were found to vary within the range of 5.5 to $20.5 \mathrm{MPa}$, which appears reasonable for this type of materials. The reduction in the interfacial shear strength with increasing content of plasticizer is likely to be related to the softening of matrix, as well as to chemical interactions of the fibers and starch matrix becoming increasingly mediated by plasticizer molecules due to dilution of the matrix. In general, it can be concluded that a good 


\section{ACCEPTED MANUSCRIPT}

level of fiber/matrix adhesion has been achieved, as expected for the chemically compatible constituents, since a close correlation between the interfacial shear strength and the yield strength of the neat polymer was observed, with the former being greater or equal to the latter.

\section{Acknowledgement}

J. Andersons acknowledges the funding by ESF via project 2013/0025/1DP/1.1.1.2.0/13/ APIA/VIAA/019.

\section{Appendix. Elementary derivation of the length efficiency factor for continuous fiber length distribution}

The stress-strain relation in tension of a composite reinforced with short misaligned fibers of variable length, proposed by Bowyer and Bader [12] based on the Kelly-Tyson model of stress transfer [30], in the notation introduced above, reads as

$$
\sigma_{c}=\eta_{o}\left[\sum_{k}^{l_{k}<l_{c}} \frac{\tau_{i} l_{k} v_{k}}{2 r_{f}}+\sum_{j}^{l_{j}>l_{c}} E_{f} \varepsilon\left(1-\frac{E_{f} \varepsilon r_{f}}{2 l_{j} \tau_{i}}\right) v_{j}\right]+E_{m} \varepsilon\left(1-v_{f}\right) .
$$

In deriving Eq. (A.1), the continuous spectrum of lengths of reinforcing fibers is divided into subfractions [12]; the contribution of subfractions with a length smaller than the critical length $l_{c}$ is given by the sum over $k$ in Eq. (A.1) and that with fibers longer than $l_{c}$ - by the sum over $j$. The volume fraction of the fibers belonging to a $k$ th subfraction of fiber length is designated by $v_{k}$; it is assumed that $\eta_{o}$ is independent of strain and fiber length, and the fibers have a constant radius $r_{f}$.

In the following, we transform Eq. (A.1) to explicitly allow for continuous length distribution of reinforcing fibers characterized by a distribution density function $p(l)$. First, Eq. (A.1) is rearranged into a more compact form making use of the expression for fiber length efficiency factor $\eta_{l}^{*}(l)$ given by Eq. (18): 
$\sigma_{c}=\eta_{o} v_{f} E_{f} \varepsilon \sum_{j} \eta_{l}^{*}\left(l_{j}\right) \frac{\Delta v_{j}}{v_{f}}+E_{m} \varepsilon\left(1-v_{f}\right)$

where $\Delta v_{j}$ denotes the volume fraction in the composite of the subfraction of fibers of length in the interval of $l_{j} \ldots l_{j}+\Delta l$, with $\Delta l$ being an arbitrarily small length increment. The volume fraction $\Delta v_{j}$ is equal to the ratio of the respective fiber volume, given by the product of the volume of a single fiber $l_{j} \pi r_{f}^{2}$ and the number of fibers $\Delta N\left(l_{j}\right)$ of length $l_{j} \ldots l_{j}+\Delta l$, and composite volume $V_{c}, \Delta v_{j}=l_{j} \pi r_{f}^{2} \Delta N\left(l_{j}\right) / V_{c}$. Similarly, the total volume of fibers in the composite can be expressed as the product of the total number of fibers $N$ and the average fiber volume $\left\langle l \pi r_{f}^{2}\right\rangle=\langle l\rangle \pi r_{f}^{2}$, hence the fiber volume fraction is $v_{f}=\langle l\rangle \pi r_{f}^{2} N / V_{c}$. Combining the above expressions yields $\frac{\Delta v_{j}}{v_{f}}=\frac{l_{j}}{\langle l\rangle} \frac{\Delta N\left(l_{j}\right)}{N}$. The fraction of the fibers of length in the interval of $l_{j} \ldots l_{j}+\Delta l, \Delta N\left(l_{j}\right) / N$, is equal to the probability $\Delta P\left(l_{j}\right)$ that an arbitrarily selected fiber belongs to the given length interval. The latter is related to the distribution density of the reinforcing fiber length as $\Delta P\left(l_{j}\right)=p\left(l_{j}\right) \Delta l$. Hence, the relative volume fraction $\Delta v_{j} / v_{f}$ of the fibers belonging to a $j$ th subfraction is

$$
\frac{\Delta v_{j}}{v_{f}}=\frac{l_{j}}{\langle l\rangle} p\left(l_{j}\right) \Delta l
$$

Substituting Eq. (A.3) into Eq. (A.2) and replacing the summation over the subfractions of fiber length, in the limit of $\Delta l \rightarrow 0$, by integration over fiber length, we finally arrive at

$$
\sigma_{c}=\eta_{o} v_{f} E_{f} \varepsilon \int_{0}^{\infty} \eta_{l}^{*}(l) \frac{l}{\langle l\rangle} p(l) d l+E_{m} \varepsilon\left(1-v_{f}\right)
$$

Comparing Eqs. (1) and (A.4), it becomes apparent that the fiber length efficiency factor $\eta_{l}$ for a continuous distribution of fiber length is given by Eq. (6), as derived in [37] using the scan line method. 


\section{ACCEPTED MANUSCRIPT}

\section{References}

1. Faruk O, Bledzki AK, Fink H-P, Sain M. Biocomposites reinforced with natural fibers: 2000-2010. Prog Polym Sci 2012; 37: 1552-1596.

2. Faruk O, Bledzki AK, Fink H-P, Sain M. Progress report on natural fiber reinforced composites. Macromol Mater Eng 2014; 299: 9-26.

3. Zini E, Scandola M. Green composites: an overview. Polym Compos 2011; 32: 19051915.

4. Sahari J, Sapuan SM. Natural fibre reinforced biodegradable polymer composites. Rev Adv Mater Sci 2011; 30: 166-174.

5. Shah DU. Developing plant fibre composites for structural applications by optimising composite parameters: a critical review. J Mater Sci 2013; 48: 6083-6107.

6. Nättinen K, Hyvärinen S, Joffe R, Wallström L, Madsen B. Naturally compatible: starch acetate/cellulosic fiber composites. I. Processing and properties. Polym Compos 2010; 31: 524-535.

7. Madsen B, Joffe R, Peltola H, Nättinen K. Short cellulosic fiber/starch acetate composites - micromechanical modeling of Young's modulus. J Compos Mater 2011; 45: 2119- 2131.

8. Joffe R, Madsen B, Nättinen K, Miettinen A. Strength of cellulosic fiber/starch acetate composites with variable fiber and plasticizer content. J Compos Mater 2014, DOI: $10.1177 / 0021998314528734$

9. Drzal LT, Herrera-Franco PJ, Ho H. Fiber-Matrix Interface Tests, in: Comprehensive Composite Materials, Elsevier Science Ltd., 2000, Vol. 5, pp. 71-111.

10. Graupner N, Rößler J, Ziegmann G, Müssig J. Fibre/matrix adhesion of cellulose fibres in PLA, PP and MAPP: A critical review of pull-out test, microbond test and single fibre fragmentation test results. Compos: Part A 2014; 63: 133-148. 


\section{ACCEPTED MANUSCRIPT}

11. Thomason JL. Interfacial strength in thermoplastic composites - at last an industry friendly measurement method? Compos: Part A 2002; 33: 1283-1288.

12. Bowyer WH, Bader MG. On the reinforcement of thermoplastics by imperfectly aligned discontinuous fibres. J Mater Sci 1972; 7: 1315-1321.

13. Bader MG, Bowyer WH. An improved method of production for high strength fibrereinforced thermoplastics. Compos. 1973; 4: 150-156.

14. Thomason JL. Micromechanical parameters from macromechanical measurements on glass reinforced polyamide 6,6. Compos Sci Technol 2001; 61: 2007-2016.

15. Thomason JL. Micromechanical parameters from macromechanical measurements on glass-reinforced polybutyleneterepthalate. Compos: Part A 2002; 33: 331-339.

16. Thomason JL. Micromechanical parameters from macromechanical measurements on glass reinforced polypropylene. Compos Sci Technol 2002; 62: 1455-1468.

17. Isitman NA, Aykol M. Continuum micro-mechanics of estimating interfacial shear strength in short fiber composites. Compos Interf 2010; 17: 49-58.

18. Isitman NA, Aykol M, Ozkoc G, Bayram G, Kaynak C. Interfacial strength in short glass fiber reinforced acrylonitrile-butadiene-styrene/polyamide 6 blends. Polym Compos 2010; 31: 392-398.

19. Bos HL, Müssig J, van den Oever MJA. Mechanical properties of short-flax-fibre reinforced compounds. Compos: Part A 2006; 37: 1591-1604.

20. Modniks J, Poriķe E, Andersons J, Joffe R. Evaluation of the apparent interfacial shear strength in short-flax-fiber/PP composites. Mech Compos Mater 2012; 48: 571-578.

21. Lafranche E, Oliveira VM, Martins CI, Krawczak P. Prediction of injection-moulded flax fibre reinforced polypropylene tensile properties through a micro-morphology analysis. $\mathbf{J}$ Compos Mater 2013; doi: 10.1177/0021998313514875. 


\section{ACCEPTED MANUSCRIPT}

22. Li Y, Pickering KL, Farrell RL. Determination of interfacial shear strength of white rot fungi treated hemp fibre reinforced polypropylene. Compos Sci Technol 2009; 69: 11651171.

23. Vallejos ME, Espinach FX, Julián F, Torres Ll., Vilaseca F, Mutjé P. Micromechanics of hemp strands in polypropylene composites. Compos Sci Technol 2012; 72: 1209-1213.

24. Etaati A, Pather S, Cardona F, Wang H. Injection molded noil hemp fiber composites: interfacial shear strength, fiber strength, and aspect ratio. Polym Compos 2014; DOI: $10.1002 /$ pc.23172.

25. Rodriguez M, Rodrigues A, Bayer R J, Vilaseca F, Girones J, Mutje P. Determination of corn stalk fibers' strength through modeling of the mechanical properties of its composites. BioRes 2010; 5: 2535-2546.

26. López JP, Méndez JA, El Mansouri N-E, Mutjé P, Vilaseca F. Mean intrinsic tensile properties of stone groundwood fibers from softwood. BioRes 2011; 6: 5037-5049.

27. Serrano A, Espinach FX, Julian F, del Rey R, Mendez JA, Mutje P. Estimation of the interfacial shear strength, orientation factor and mean equivalent intrinsic tensile strength in old newspaper fiber/polypropylene composites. Compos: Part B 2013; 50: 232-238.

28. Reixach R, Franco-Marquès E, El Mansouri N-E, de Cartagena F R, Arbat G, Espinach FX, Mutjé P. Micromechanics of mechanical, thermomechanical, and chemithermomechanical pulp from orange tree pruning as polypropylene reinforcement: A comparative study. BioRes 2013; 8: 3231-3246.

29. Lopez JP, Vilaseca F, Barberà L, Bayer RJ, Pèlach MA, Mutjé P. Processing and properties of biodegradable composites based on Mater-Bi ${ }^{\circledR}$ and hemp core fibres. Res Conserv Recycl 2012; 59: 38-42.

30. Kelly A, Tyson WR. Tensile properties of fibre-reinforced metals. J Mech Phys Solids $1965 ; 13: 329-350$ 


\section{ACCEPTED MANUSCRIPT}

31. Modniks J, Andersons J. Modeling the non-linear deformation of a short-flax-fiberreinforced polymer composite by orientation averaging. Compos: Part B 2013; 54: 188193.

32. Notta-Cuvier D, Lauro F, Bennani B, Balieu R. An efficient modelling of inelastic composites with misaligned short fibres. Int J Solids Struct 2013; 50: 2857-2871.

33. Notta-Cuvier D, Lauro F, Bennani B. An original approach for mechanical modelling of short-fibre reinforced composites with complex distributions of fibre orientation. Compos: Part A 2014; 62: 60-66.

34. Notta-Cuvier D, Lauro F, Bennani B, Balieu R. Damage of short-fibre reinforced materials with anisotropy induced by complex fibres orientations. Mech Mater 2014; 68: $193-206$.

35. Cox HL. The elasticity and strength of paper and other fibrous materials. Br J Appl Phys 1952; 3: 72-79.

36. Tucker III CL, Liang E. Stiffness predictions for unidirectional short-fiber composites: Review and evaluation. Compos Sci Technol 1999; 59: 655-671.

37. Jayaraman K, Kortschot MT. Correction to the Fukuda-Kawata Youngs's modulus theory and the Fukuda-Chou strength theory for short fibre-reinforced composite materials. J Mater Sci 1996; 31: 2059-2064.

38. Kim J-K, Zhou L, Mai Y-W. Stress transfer in the fibre fragmentation test. Part I An improved analysis based on a shear strength criterion. J Mater Sci 1993; 28: 6233-6245.

39. Hine P, Parveen B, Brands D, Caton-Rose F. Validation of the modified rule of mixtures using a combination of fibre orientation and fibre length measurements. Compos: Part A 2014; 64: 70-78.

40. Madsen B, Thygesen A, Lilholt H. Plant fibre composites - porosity and stiffness. Compos Sci Technol 2009; 69: 1057-1069. 


\section{ACCEPTED MANUSCRIPT}

41. Czigány T, Morlin B, Mezey Z. Interfacial adhesion in fully and partially biodegradable polymer composites examined with microdroplet test and acoustic emission. Compos Interf 2007; 14: 869-878.

42. Cañigueral N, Vilaseca F, Méndez JA, López JP, Barberà L, Puig J, Pèlach MA, Mutjé P. Behavior of biocomposite materials from flax strands and starch-based biopolymer. Chem Eng Sci 2009; 64: 2651-2658.

43. Joffe R, Andersons J, Wallström L. Strength and adhesion characteristics of elementary flax fibres with different surface treatments. Compos: Part A 2003; 34: 603-612.

44. Joffe R, Andersons J, Wallström L. Interfacial shear strength of flax fiber/thermoset polymers estimated by fiber fragmentation tests. J Mater Sci 2005; 40: 2721-2722.

45. Averous L, Boquillon N. Biocomposites based on plasticized starch: thermal and mechanical behaviours. Carbohydrate Polym 2004; 56: 111-122.

46. Thomason JL. Structure-property relationships in glass-reinforced polyamide, Part 1: The effects of fiber content. Polym Compos 2006; 27: 552-562

47. Thomason JL. The influence of fibre length and concentration on the properties of glass fibre reinforced polypropylene: 7. Interface strength and fibre strain in injection moulded long fibre PP at high fibre content. Compos: Part A 2007; 38: 210-216.

48. Isitman NA, Aykol M, Kaynak C. Interactions at fiber/matrix interface in short fiber reinforced amorphous thermoplastic composites modified with micro- and nano-fillers. J Mater Sci 2012; 47: 702-710.

49. Sui GX, Wong S-C, Yang R, Yue CY. The effect of fiber inclusions in toughened plastics - Part II: determination of micromechanical parameters. Compos Sci Technol 2005; 65: 221-229. 


\section{ACCEPTED MANUSCRIPT}

50. Gironès J, Espinach FX, Pellicer N, Tresserras J, Alcalà M, Mutjé P. High-performancetensile-strength alpha-grass reinforced starch-based fully biodegradable composites. BioRes 2013; 8: 6121-6135.

51. Thomason JL, Yang L. Temperature dependence of the interfacial shear strength in glassfibre polypropylene composites. Compos Sci Technol 2011; 71: 1600-1605.

52. Nairn JA. Thermoelastic analysis of residual stresses in unidirectional, high-performance composites. Polym Compos 1985; 6: 123-130.

53. Thomason JL. Dependence of interfacial strength on the anisotropic fiber properties of jute reinforced composites. Polym Compos 2010; 31: 1525-1534. 


\section{ACCEPTED MANUSCRIPT}

Table 1. Characteristics of constituents.

\begin{tabular}{|c|c|c|c|c|c|c|}
\hline Composite & Plasticizer & Plasticizer & Yield & Fiber & Fiber & Fiber \\
& type & fraction in & strength of & loading in & aspect & diameter, \\
& & matrix, & matrix, & composite, & ratio & $\mu \mathrm{m}$ \\
\hline C15 & PSA2.1 & 20 & $22.6 \pm 1.2$ & 10 & 19 & 18 \\
\hline C16 & PSA2.1 & 20 & $22.6 \pm 1.2$ & 40 & 8 & 19 \\
\hline C17 & PSA2.2 & 20 & $23.2 \pm 1.1$ & 40 & 9 & 17 \\
\hline C20 & PSA3 & 25 & $17.1 \pm 0.3$ & 10 & 19 & 17 \\
\hline C21 & PSA3 & 25 & $17.1 \pm 0.3$ & 40 & 15 & 17 \\
\hline C28 & PSA5.1 & 32.5 & $6.6 \pm 0.2$ & 10 & 18 & 19 \\
\hline C29 & PSA5.1 & 32.5 & $6.6 \pm 0.2$ & 40 & 15 & 19 \\
\hline C37 & PSA6 & 35 & $3.9 \pm 0.3$ & 10 & 28 & 18 \\
\hline C38 & PSA6 & 35 & $3.9 \pm 0.3$ & 40 & 17 & 17 \\
\hline
\end{tabular}




\section{ACCEPTED MANUSCRIPT}

Table 2. Characteristics of composites.

\begin{tabular}{|c|c|c|c|c|c|c|}
\hline \multirow[t]{2}{*}{$\begin{array}{l}\text { Composite } \\
\text { designation }\end{array}$} & \multicolumn{2}{|c|}{$\begin{array}{l}\text { Parameters of } \\
\text { fiber length } \\
\text { distribution, Eq. } \\
\text { (20) }\end{array}$} & \multirow[t]{2}{*}{$\begin{array}{l}\text { Length } \\
\text { efficiency } \\
\text { factor } \eta_{l} \text {, } \\
\text { (Eq. (6)) }\end{array}$} & \multirow[t]{2}{*}{$\begin{array}{l}\text { Orientation } \\
\text { factor } \eta_{o} \\
\text { (Eq. (22)) }\end{array}$} & \multirow[t]{2}{*}{$\begin{array}{c}\mathrm{IFSS}_{\mathrm{ep}} \\
\mathrm{MPa}\end{array}$} & \multirow[t]{2}{*}{$\begin{array}{c}\mathrm{IFSS}_{\mathrm{rp}} \\
\mathrm{MPa}\end{array}$} \\
\hline & $\alpha$ & $l_{W}, \mathrm{~mm}$ & & & & \\
\hline C15 & 1.5 & 0.39 & 0.69 & $0.43 \pm 0.02$ & $12.1 \pm 0.6$ & $11.3 \pm 0.6$ \\
\hline C16 & 1.6 & 0.17 & 0.55 & $0.59 \pm 0.01$ & $21.8 \pm 0.8$ & $16.1 \pm 0.7$ \\
\hline C17 & 1.7 & 0.17 & 0.59 & $0.58 \pm 0.01$ & $20.6 \pm 1.6$ & $16.0 \pm 1.6$ \\
\hline $\mathrm{C} 20$ & 1.3 & 0.35 & 0.64 & $0.35 \pm 0.02$ & $10.1 \pm 0.7$ & $9.6 \pm 0.7$ \\
\hline $\mathrm{C} 21$ & 1.4 & 0.28 & 0.69 & $0.40 \pm 0.01$ & $13.3 \pm 0.7$ & $12.1 \pm 0.6$ \\
\hline C28 & 1.4 & 0.37 & 0.46 & $0.48 \pm 0.03$ & $8.1 \pm 0.5$ & $7.3 \pm 0.4$ \\
\hline $\mathrm{C} 29$ & 1.3 & 0.32 & 0.58 & $0.41 \pm 0.01$ & $8.9 \pm 0.2$ & $8.0 \pm 0.2$ \\
\hline C37 & 1.1 & 0.52 & 0.55 & $0.32 \pm 0.01$ & $5.6 \pm 0.1$ & $5.4 \pm 0.1$ \\
\hline C38 & 1.3 & 0.32 & 0.52 & $0.41 \pm 0.01$ & $6.9 \pm 0.1$ & $6.0 \pm 0.2$ \\
\hline
\end{tabular}


a)

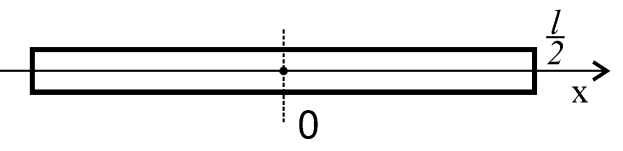

b)

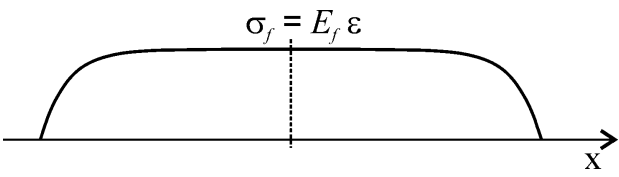

c)

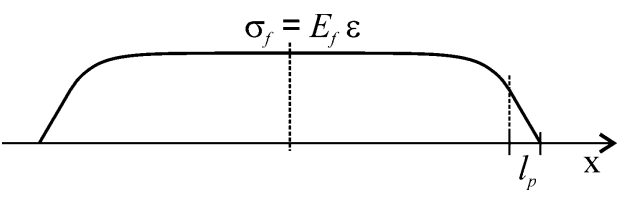

Fig. 1. Schematic of a fiber (a) and the axial stress distribution along it in the case of elastic (b) and elastic-perfectly plastic (c) interfacial stress transfer.

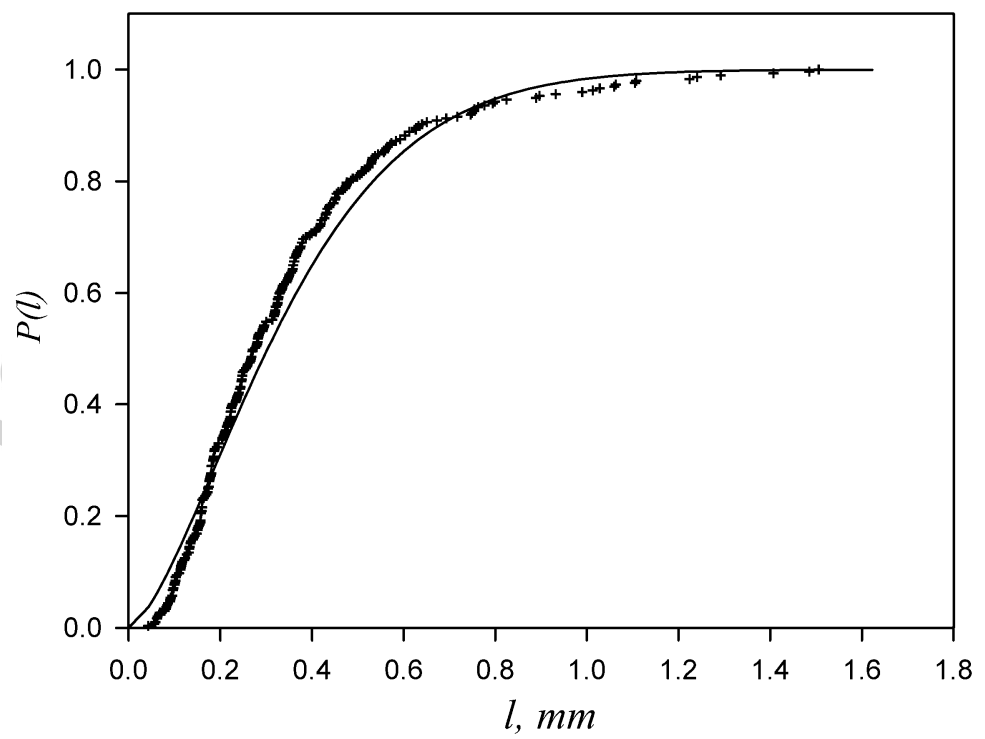

Fig. 2. Empirical length distribution of fibers extracted from composite C15 and its approximation by the two-parameter Weibull distribution, Eq. (20). 


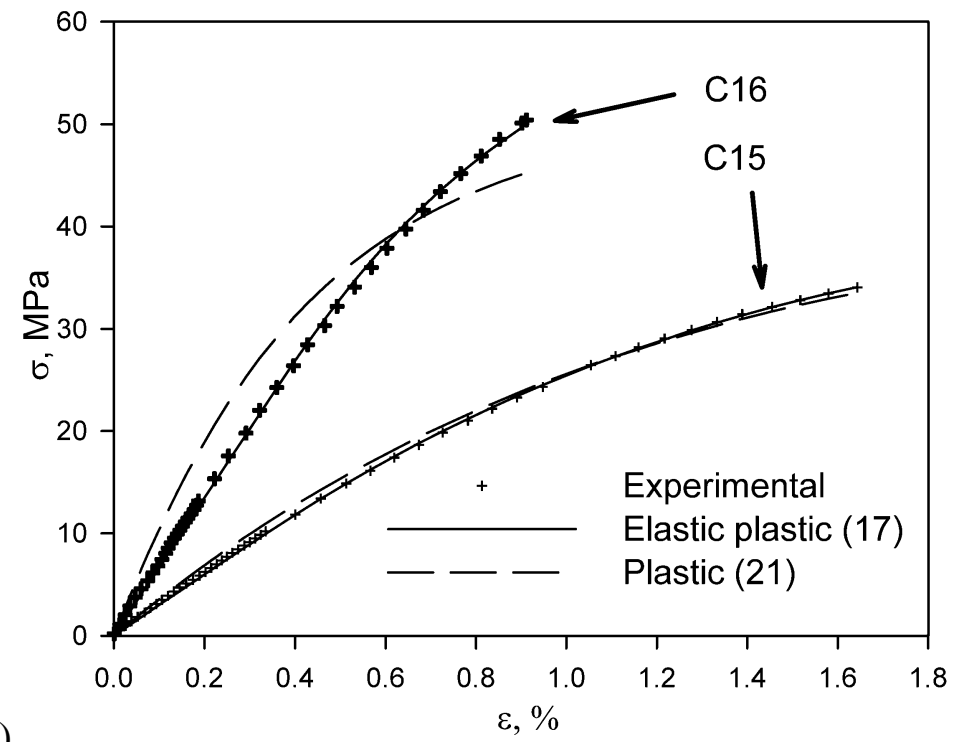

a)

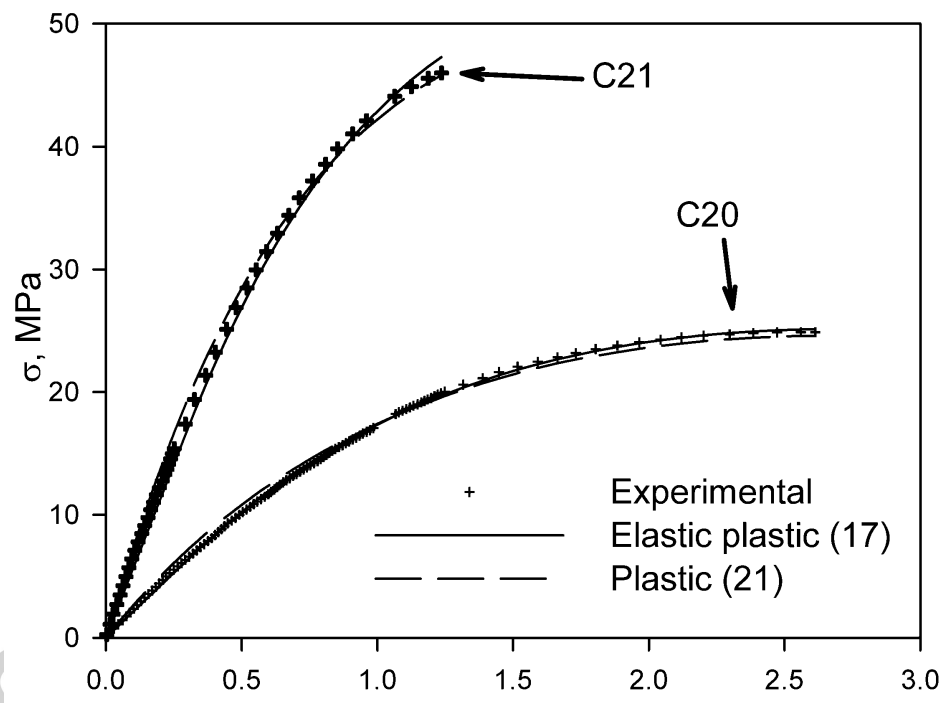

b)

$\varepsilon, \%$ 


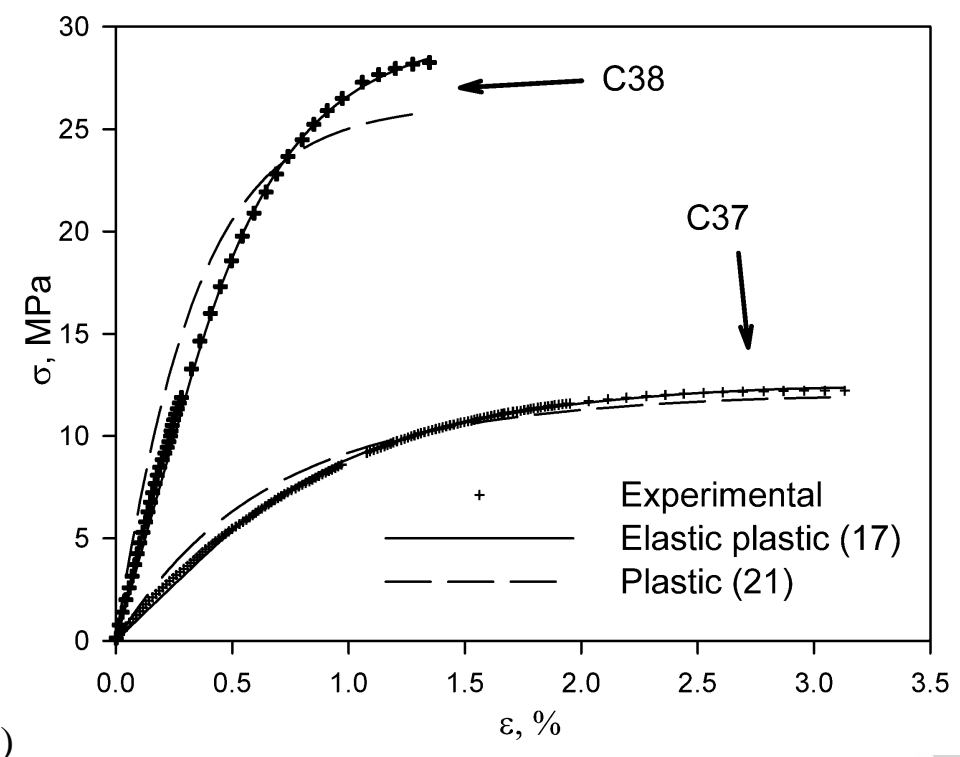

Fig. 3. Typical stress-strain diagrams of composites with the plasticizer fractions in the matrix of 20 (a), 25 (b), and 35 (c) wt. \% and their approximation by Eq. (1) assuming the elasticperfectly plastic (solid lines) and rigid-perfectly plastic (dashed lines) interfacial stress transfer by shear. 


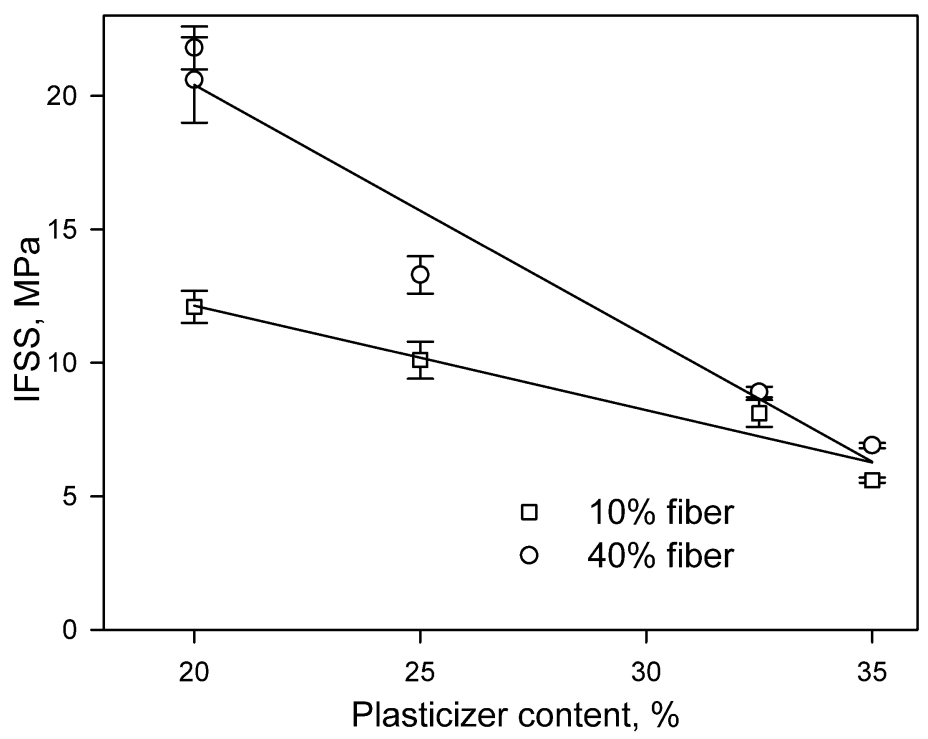

Fig. 4. Variation of the apparent IFSS $_{\mathrm{ep}}$ with plasticizer content in the matrix for fiber loadings of $10(\square)$ and $40 \mathrm{wt} . \%(\circ)$; the solid lines show the respective linear regression relations.

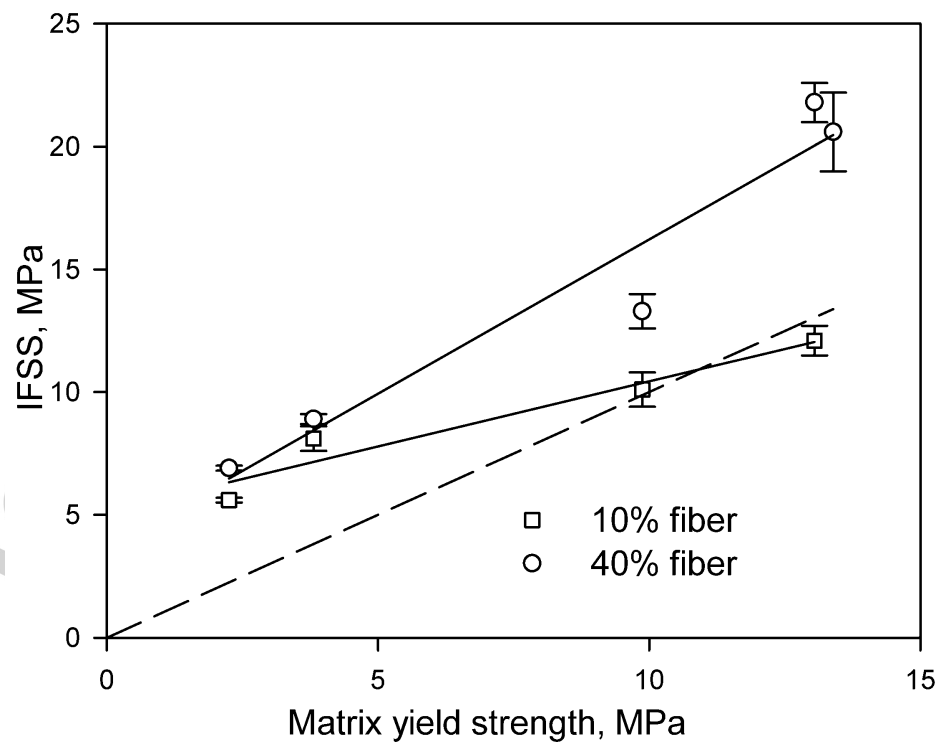

Fig. 5. Variation of the apparent IFSS $_{\mathrm{ep}}$ with shear yield strength of the matrix for fiber loadings of $10(\square)$ and $40 \mathrm{wt} . \%(\circ)$; the solid lines show the respective linear regression relations. The dashed line corresponds to the locus of equal IFSS and matrix yield strength. 